\title{
Relative effects of acoustic and semantic relatedness on clustering in free recall*
}

\author{
DAVID LONG and GORDON A. ALLEN $\dagger$ \\ Miami University, Oxford, Ohio 45056
}

An 18-word list was constructed so that each word belonged to both a semantically related category and an acoustically related category. The list was presented, either orally or visually, in a multitrial free-recall task. The results from 40 Ss showed that the organization of recall was dominated by the acoustic properties of the words.

While the effectiveness of semantic relatedness as a variable in free recall has been well documented (see, e.g., Shuell, 1969), there has been some controversy as to whether acoustic relatedness is also an effective variable. Bousfield \& Wicklund (1969) found that rhyme was a determinant of clustering in free recall. However, Forrester \& King (1971), using a mixed-list design, found no evidence for acoustic clustering, although they did find semantic clustering. It was also observed that acoustically related words were no better recalled than control words, while the semantically related words were, of course, recalled better.

The purpose of the present experiment was to determine the relative effectiveness of the two variables. To accomplish this end, a list of words was constructed such that each word belonged to both a semantic category and an acoustic category. The list was presented using a multitrial free-recall paradigm. The list was presented either orally or visually to determine whether there was an interaction between presentation mode and the dimension Ss used to cluster their recall.

\section{METHOD}

Subjects

The Ss were 20 men and 20 women from the introductory psychology S pool at Miami University. These Ss volunteered in order to fulfill a course requirement.

\section{Materials and Design}

The list of words used as stimuli is shown in Table 1. The list of 18 words can be partitioned into six sets of three words in two ways: according to semantic category or according to rhyme. The list was generated by several people thinking of appropriate words. It should be noted that most of the acoustically related words end with the same sequence of letters.

The same list of stimuli was presented to all Ss. There were two independent groups of Ss in the experiment. For one group of $20 \mathrm{Ss}$, the list was presented visually; for the remainder, the list was read to the Ss.

*This research was supported in part by a Miami University faculty research grant to the second author. The paper is sponsored by John C. Jahnke, who takes full editorial responsibility for its contents.

tRequests for reprints should be sent to Gordon A. Allen, Department of Psychology, Miami University, Oxford, Ohio 45056 .

\section{Procedure}

The Ss were assigned to either the visual or aural group randomly, with the constraint that an equal number of males and females were assigned to both groups. The Ss, who were tested individually, were asked to memorize a list of words. They were told they could recall the words in any order. No mention was made of the construction of the list.

Each word in the list was printed on a $5 \times 7$ in. index card; each letter was 2 in. high. For the visual group, the list was presented to the $S$ by holding up each card for $1 \mathrm{sec}$. For the aural group, the list was presented by the $\mathrm{E}$, who slowly and distinctly pronounced each word, pausing after each word to allow a 1-sec presentation rate. Time was measured by a Lafayette metronome, set at 2 beats/sec. After the last word had been presented, the $S$ was handed a piece of paper with 18 lines on which to respond. While $S$ was recalling the list, the deck of cards was shuffled, and the procedure was repeated until $\mathrm{S}$ had recalled all 18 words on two consecutive trials. The time taken by the $S$ to recall the words during the second correct recall trial was recorded. After the $S$ met the learning criterion, he was asked to recall the words a third time but to arrange the words according to the alternate schema of clustering, that is, by concept if he had been using rhyme, or vice versa. It was the E's decision as to whether the $S$ had been clustering according to rhyme or concept; $\mathrm{E}$ had little trouble making the decision. The time required by the $S$ to recall the words this third time was measured. $\mathrm{S}$ was then told about the experiment and thanked.

\section{RESULTS}

The mean number of trials to the criterion of two correct recitations was 11.65 and 10.95 , respectively, for the visual and aural groups. This difference can be considered statistically insignificant, $\mathrm{t}(38)=.49$, $\mathrm{p}>.05$.

The measure of clustering used in the analysis was a version of the runs test developed by Frankel \& Cole (1970). The measure, a $\mathrm{z}$ score, is based upon a comparison between the observed number of runs (strings of categorized words) and the expected number of runs assuming chance responding. This particular measure was used because it is independent of the number of words recalled.

Each S's protocol was scored twice, once to obtain a measure of acoustic relatedness and once again to obtain a measure of semantic relatedness. The $\mathrm{z}$ score, when calculated, is negative if there are more runs than would be expected by chance; for simplicity, the signs have been reversed for presentation here.

Table 1

Stimulus List

\begin{tabular}{lll}
\hline Ted & Red & Head \\
Jack & Black & Back \\
Jean & Green & Spleen \\
Cow & Chow & Plow \\
Snail & Ale & Nail \\
Snake & Cake & Rake \\
\hline
\end{tabular}




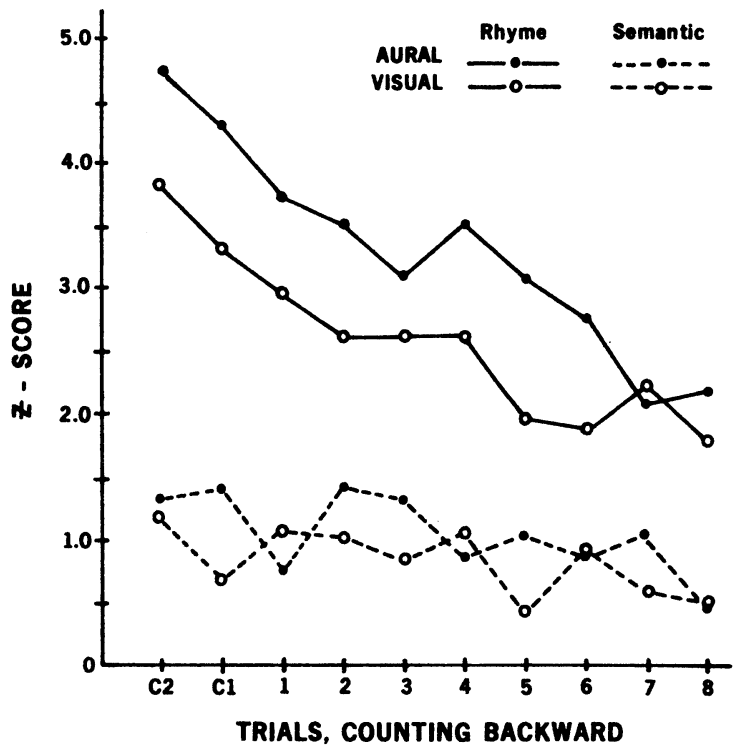

Fig. 1. z scores as a function of trials, plotted backwards.

The mean $\mathrm{z}$ scores per trial using both methods of scoring are shown in Fig. 1 for each of the experimental groups. Since Ss were run to a criterion and the data at the end of learning were of prime interest, the $\mathrm{z}$ scores are plotted as a backward curve; Trial 2 in the figure is the second trial before the criterion trials. The curves have been truncated after eight trials, since the number of Ss dropped below 15 per experimental group.

For the statistical analysis of the data in Fig. 1, the measure used was the difference between the $\mathrm{z}$ score for acoustic relatedness and the $\mathrm{z}$ score for semantic relatedness. If there were no preference for the

Table 2

Proportion of Times a Given Word Was Followed by a Word Belonging to the Same Rhyme Set, the Same Semantic Set, or a Nonrelated Set on the Second Criterion Trial

\begin{tabular}{lccc}
\hline & \multicolumn{3}{c}{ Category of } \\
\cline { 2 - 4 } Word & Rhyme & Semantic & Nonrelated \\
\hline Cow & .57 & .05 & .38 \\
Chow & .70 & .08 & .22 \\
Plow & .58 & .08 & .33 \\
Ted & .36 & .38 & .26 \\
Red & .33 & .46 & .21 \\
Head & .25 & .31 & .44 \\
Black & .55 & .24 & .21 \\
Back & .28 & .23 & .49 \\
Jack & .31 & .33 & .36 \\
Green & .61 & .29 & .10 \\
Jean & .33 & .36 & .31 \\
Spleen & .21 & .15 & .64 \\
Snail & .70 & .18 & .12 \\
Ale & .30 & .19 & .51 \\
Nail & .51 & .08 & .41 \\
Rake & .62 & .05 & .33 \\
Snake & .36 & .33 & .31 \\
Cake & .51 & .09 & .40 \\
\hline
\end{tabular}

dimension on which to cluster, this difference should equal zero on the second criterion trial. The obtained mean difference, 2.98 , was sufficient to reject this hypothesis, $t=3.87, p<.01$. Since the mean difference was positive, the preference was to cluster words according to acoustic relatedness.

The difference scores were also analyzed using a two-factor analysis of variance with one repeated measure. The nonrepeated factor was the modality of stimulus presentation and the repeated measure was trial number, counted backwards. For the analysis only the last six trials were included, so that each cell had the same number of Ss.

The main effect of trials was statistically significant $[F(5,200)=2.98, \mathrm{p}<.05]$, indicating that, as the experiment progressed, clustering according to acoustic relatedness increased. There was neither an effect due to the modality of presentation $[F(1,39)=.74, p>.05]$ nor a Modality by Trial interaction $[\mathrm{F}(5,200)=.49$, $p>.05]$.

On the second criterion trial, the proportion of Ss whose $\mathrm{z}$ score of acoustic relatedness was greater than 1.96 was .85 and .80 , respectively, for the aural and visual groups.

All Ss recalled the entire list without error on the reverse clustering trial after the two criterion trials. All Ss in the aural group were able to use the appropriate dimension to cluster their responses; all but three Ss in the visual group were able to do the same. Of the three Ss in the visual group who did not cluster perfectly, two had used the acoustic dimension during learning of the list. The time taken by Ss to recall the list increased markedly from the last criterion trial to the reversal trial-50 to $148 \mathrm{sec}[\mathrm{F}(1,38)=186.6, \mathrm{p}<.01]$.

The effectiveness of rhyme varied among the six sets of words. In order to obtain a measure of this variability, the frequency with which a given word was followed by another word was tabulated for the second criterion trial. For presentation, the matrix has been collapsed over the two groups of Ss, and the successor words have been classified as being in the same acoustic set, in the same semantic set, or in a nonrelated set. The frequencies were converted to proportions and are shown in Table 2.

\section{DISCUSSION}

It might be argued that acoustic relatedness was not the important dimension; rather, typographical similarity between the words was important. While the two dimensions were completely confounded in the experimental list, there was evidence that it was rhyme which was important. If typographical similarity were important, one would expect more clustering using a visual than an oral presentation. This expectation was not confirmed; rather, there was, if anything, a tendency for the aural group to have higher $\mathrm{z}$ scores.

The performance on the reversal trial, during which the $S$ was asked to categorize the words using the dimension not used during original learning, was impressive. The theory which can most easily account for this performance is that of Slamecka (1968). This theory assumes that items are stored independently, 
along with a description of the list structure which is used to generate a retrieval plan. In the present experiment, at the time of the reversal trial the $\mathrm{E}$ gave a new description of the list to $\mathrm{S}$, who used it to recall the stored words.

It must be stated, however, that any theory could account for the results, owing in part to the procedure used. On all recall trials, a lined sheet of paper was used by the $S$ to record his responses. This paper was kept in view during the entire recall trial, allowing $S$ to recall a word, then continue through his associative network until a suitable word was found to be emitted.

It must be kept in mind that the list of words used in this experiment was a unique list and that the results are not necessarily generalizable to any other list. However, it is clear that rhyme can be a powerful determinant of clustering in free recall.

\section{REFERENCES}

Bousfield, W. A., \& Wicklund, D. A. Rhyme as a determinant of clustering. Psychonomic Science, 1969, 16, 183-184.

Forrester, W. E., \& King, D. J. Effects of semantic and acoustic relatedness on free recall and clustering. Journal of Experimental Psychology, 1971, 88, 16-19.

Frankel, F., \& Cole, M. Measures of category clustering in free recall. Psychological Bulletin, 1971, 76, 39-44.

Shuell, T. J. Clustering and organization in free recall. Psy chological Bulletin, 1969, 72, 353-374.

Slamecka, N. J. An examination of trace storage in free recall. Journal of Experimental Psychology, 1968, 76, 504-513.

(Received for publication February 7, 1973.) 